J. Lake Sci.(湖泊科学), 2020, 32(2): 553-563

DOI 10. 18307/2020. 0223

(c) 2020 by Journal of Lake Sciences

\title{
太湖流域城市化对平原河网水系结构与连通性影响”
}

\author{
魏荃菳 ${ }^{1,2}$, 李一平 ${ }^{1,2 * *}$, 翁晟琳 ${ }^{1,2}$, 徐芸蔚 ${ }^{1,2}$, 朱 立 $^{3}$ \\ ( 1 : 河海大学环境学院, 南京 210098$)$ \\ ( 2 : 河海大学浅水湖泊综合治理与资源开发教育部重点实验室,南京 210098) \\ (3:张家港市水资源管理处,张家港 215617)
}

\begin{abstract}
摘 要: 太湖流域的快速城市化使河流形态发生了改变,影响了平原河网水系结构与连通性. 本文以近几年城市化发展 较为迅速的张家港地区为例, 基于景观生态学和图论的相关理论, 利用 2002 与 2015 年的水系数据, 对全区以及各行政分 区水面率、河网密度、河频率等指标进行研究, 旨在揭示该地区河网水系结构与连通性参数变化及城市化对其影响. 结果 表明: 研究区 2015 年与 2002 年相比全区各水系结构指标都呈减小趋势, 水面率、河网密度、河频率的衰减率分别为 $15.7 \% 、 12.6 \% 、 33.3 \%$, 河网有主干化趋势, 干流面积与长度发育的同步性较好; 不同行政区的水系变化有明显的空间分 异,张家港南部水系较北部水面率、河频率衰减更剧烈; 东北部地区河网密度与河网复杂度变化明显; 张家港全区河网连 通性略有提高, 但地区分异明显, 沿江的西北部地区河网连通能力有所加强, 而东南部内河区域河网畅通程度减弱, 被圩 区、水闸与泵站切断的水系需要更合理的调度方案才能增强并维持水体的连通度; 水面率、河网密度与人口、GDP 之间相 关水平较高, 各地区水系结构参数与其变化率的空间分异和该地区人口、经济发展水平密切相关; 河网河链数、节点数受 城市化影响较大, 线点率、实际连通度的变化与城市化指标相关性较弱. 本研究可以为后期张家港地区优化水系结构及 防洪排涝建设提供基础,并帮助基于各片区的特点开展因地制宜的管理.
\end{abstract}

关键词: 平原河网;水系结构;连通性;城市化;张家港;太湖流域

\section{Impact of urbanization on stream structure and connectivity of plain river network in the Taihu Basin *}

WEI Yingying ${ }^{1,2}$, LI Yiping ${ }^{1,2 * *}$, WENG Shenglin ${ }^{1,2}$, XU Yunwei ${ }^{1,2} \& \mathrm{ZHU} \mathrm{Li}^{3}$

(1: College of Environment, Hohai University, Nanjing 210098, P.R.China)

(2: Key Laboratory of Integrated Regulation and Resource Development on Shallow Lakes, Ministry of Education, Hohai University, Nanjing 210098, P.R.China)

(3: Zhangjiagang City Water Resources Management, Zhangjiagang 215617, P.R.China)

\footnotetext{
Abstract: The rapid urbanization of Taihu Basin has changed the river morphology and affected their structure and connectivity. In order to reveal the change of stream structure, connectivity and the impact from urbanization, Zhangiagang region, which has developed rapidly in recent years, was selected for research. Based on the related theories of landscape ecology and map theory, the water surface rate, river network density, river frequency and other indicators of the whole region and administrative regions were studied using the data of 2002 and 2015. Results show that: (1) The structural indexes of river network showed decreasing trends. The attenuation rates of water surface rate, river network density and river frequency were $15.7 \%, 12.6 \%$ and $33.3 \%$, respectively. The river network was getting simpler, while the area and length development of main stream were synchronous. The change of river system in different districts varied spatially. The attenuation of water surface rate and river frequency in the south of Zhangjiagang were more severe than that in the north. The density and complexity of river network changed obviously in the northeast region. (2)

* 2019-05-24 收稿; 2019-09-03 收修改稿.

国家重点基础研发计划项目 (2017YFC0405203)、国家水体污染控制与治理科技重大专项 (2017ZX07204003)、中 央高校建设世界一流大学(学科)和特色发展引导专项资金和宁夏回族自治区重点研发计划项目 (20175046802) 联合资助.

** 通信作者;E-mail:liyiping@ hhu.edu.cn.
} 
The connectivity of river network in whole region was slightly improved with significant difference among regions. The connecting capacity of the river network in the northwest area along Yangtze River has been strengthened, while the unimpeded degree in the southeast area was weakened. The river systems cut off by polders, sluices and pumping stations need more rational scheduling schemes to enhance and maintain the connectivity of water. (3) The correlation between water surface rate, river network density, population and GDP were relatively high, and the spatial difference between the structural parameters of river system and its change rate in various regions was closely related to the population and economic development. (4) The number of river chains and nodes in river network were greatly affected by urbanization. The change of line point rate and actual connectivity were weakly correlated with urbanization indicators. This study can provide a foundation for the optimization of river network system structure, flood control, drainage construction, and help to develop management according to local conditions based on the characteristics of each area in Zhangjiagang.

Keywords: Plain river network; stream structure; connectivity; urbanization; Zhangjiagang; Taihu Basin

河湖水系虽然是自然演化的重要产物, 但是其发展过程也与人类活动息息相关 ${ }^{[1]}$, 它为人类的经济社 会发展提供了支撑, 同时也成为了受人类活动影响最强烈的生态系统之一 ${ }^{[2]}$. 城市化是各种人类活动中对 河网水系影响最明显的, 全球 $60 \%$ 的河流因为城市化而发生了形态结构的改变 ${ }^{[3]}$, 由此会带来水环境恶化、 河网调蓄能力下降等一系列问题. 因此研究城市化进程下河网水系的变化具有重要的意义.

对河网水系结构的研究是分析河网形态和功能的基础 ${ }^{[4]}$. 近年来我国对河流水系结构形态及连通性的 研究主要集中在江西 ${ }^{[5-6]}$ 、河南 ${ }^{[7]}$ 、浙东沿海 ${ }^{[8]}$ 、太湖流域 ${ }^{[9-11]}$ 等地区. 河网在城市化进程中受到破坏后, 主 要表现出河道数量减少, 河网密度下降, 河道趋于主干化等问题. 连通性是河网功能性指标之一, 现代城市 洪涝灾害的频发与河网连通性降低有关 ${ }^{[12]}$. 关于河网水系连通性的研究于 20 世纪后开始发展, 主要涉及的 理论基础包括景观生态学 ${ }^{[13]}$ 、图论 ${ }^{[14]}$ 、水文模型 ${ }^{[15]}$ 等. 已有对太湖流域地区平原河网的研究主要集中在以 自然发育河流为主的水系区域, 缺少长江中下游沿江城市典型的人工河渠与自然河流共同存在下的综合水 系河网结构及连通性的研究.

太湖流域位于长江三角洲, 该地区是我国的经济核心区之一, 同时也是河网最密集的地区之一 ${ }^{[16]}$. 本 文以太湖流域平原河网地区的沿江城市张家港为例开展研究具有典型性, 张家港在近年来城市化发展迅 速,河网结构及连通性的变化较大,因此研究该区域平原河网在城市化背景下的变化有实际意义, 有助于理 解在高强度人类活动干扰下平原河网的演变以及其对水环境、水资源带来的影响, 能为修复平原地区河网 水系结构、加强河网连通性提供重要的依据.

\section{1 研究区域概况}

张家港市 $\left(31^{\circ} 43^{\prime} 12^{\prime \prime} \sim 32^{\circ} 02^{\prime} \mathrm{N}, 120^{\circ} 21^{\prime} 57^{\prime \prime} \sim 120^{\circ} 52^{\prime} \mathrm{E}\right.$ ) 位于江苏省东南部, 北临长江, 是位于沿海及长 江三角洲经济开发区交汇地区的新兴工业城市. 张家港市全市的总面积是 $986.73 \mathrm{~km}^{2}$, 其中陆地面积为 $791.05 \mathrm{~km}^{2}$, 属于太湖流域武澄锡虞水系, 区域内河流众多、纵横交错, 形态南北各异, 南部多弯曲河流, 北部 多顺直河流 ${ }^{[17]}$, 目前境内河道总长约 $1079 \mathrm{~km}$, 属典型的平原河网地区 (图 1), 区域中河网水系为天然发育 河流与人工开挖河渠共存的综合水系. 张家港市自改革开放以来, 人均 GDP 持续增长, 工业水平飞速提升, 城市化进程显著, 在此过程中, 许多河流被淤堵、填埋, 水系形态发生了较大的改变. 本文对张家港市八镇一 区的河网水系变化进行探讨, 不考虑地理位置较为独立的双山岛旅游度假区.

\section{2 研究方法和数据基础}

由于平原地区河网密度高、复杂度高, 河流流向不定, 且有大量的人工介人, Horton、Strahler 等经典的河 流分级方法不适合直接应用 ${ }^{[9]}$, 所以按照河流宽度对河网水系进行分级, 河宽大于 $20 \mathrm{~m}$ 的为一级河流; 河 宽为 $10 \sim 20 \mathrm{~m}$ 的为二级河流; 河宽小于 $10 \mathrm{~m}$ 的为三级河流 ${ }^{[18]}$. 根据《张家港城区河道控制性详细规划》, 将 研究区范围内区域性河道与通江主干河道定义为干流.

\section{1 水系结构参数}

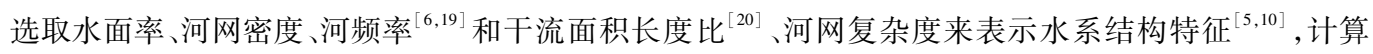




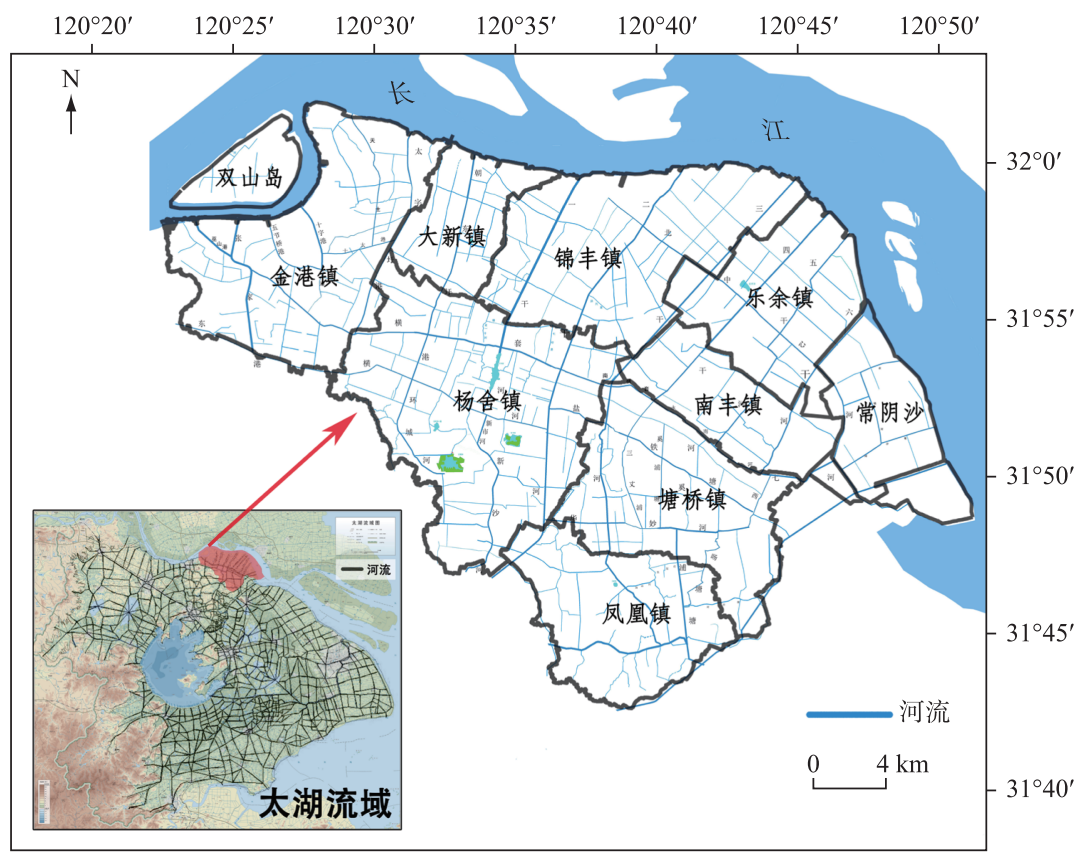

图 1 研究区示意图

Fig. 1 Location of the study area

公式如下:

$$
\begin{gathered}
W_{\mathrm{p}}=\left(A_{\mathrm{w}} / A\right) \times 100 \% \\
R_{\mathrm{d}}=L / A \\
R_{\mathrm{f}}=N / A \\
R_{\mathrm{AL}}=A_{\mathrm{m}} / L_{\mathrm{m}} \\
C R=N_{0}\left(L / L_{\mathrm{m}}\right)
\end{gathered}
$$

式中, $A_{w}$ 为水域面积; $A$ 为研究区域总面积; $L$ 为河网总长度; $N$ 为研究区内河流总数; $A_{\mathrm{m}}$ 为主干河流面积; $L_{\mathrm{m}}$ 为主干河流长度; $N_{0}$ 为河流等级数.

水面率 $\left(W_{\mathrm{P}}\right)$, 即多年平均水位下河道水体的实际水面积与区域总面积之比, 表示河流面积发育程度; 河网密度 $\left(R_{\mathrm{d}}\right)$ 是指单位流域面积上的河流长度, 本文中用研究区域河流总长度与研究区域总面积之比得 到, 表示河流长度发育程度; 河频率 $\left(R_{\mathrm{f}}\right)$ 为区域内河流数量与河网总长度之比, 表示河网数量发育程度; 干 流面积长度比 $\left(R_{\mathrm{AL}}\right)$ 为区域内主干河流面积与总长度之比, 表示主干河流长度与面积发育的不同步性.

另外, 由于高度城市化地区人为干预的增多, 河网水系的自相似性已被破坏 ${ }^{[10,21]}$, 选取河网复杂度 $(C R)$ 表征河网层次的丰富程度 ${ }^{[9]}$, 数值越大, 说明该地区河网构成的层次越丰富, 支撑干流的支流水系越 发达.

\section{2 水系连通性参数}

本文基于景观生态学中景观生态网络连接度的概念 ${ }^{[22]}$, 利用图论的相关理论对河网结构连通性进行分 析 ${ }^{[23]}$. 在河网水系中, 将河道概化为线, 将河流交汇的点定义为节点, 连接两个节点的河道定义为河链. 本 文借助图论中连通度的概念 ${ }^{[13,23-24]}$, 选取线点率 $\beta$ 和实际连通度 $\gamma$ 来计算并评价河流结构的连通性,计算公 式如下:

$$
\begin{gathered}
\beta=L_{\mathrm{e}} / N \\
\gamma=L_{\mathrm{e}} /[3(N-2)]
\end{gathered}
$$

式中, $L_{e}$ 为河网中的河链数; $N$ 为河网中的节点数. 
表 $12001-2006$ 年武澄锡虞区土地 利用类型面积变化

Tab.1 The change of each land use type area in Wuchengxiyu district from 2001 to 2006

\begin{tabular}{cccc}
\hline \multirow{2}{*}{$\begin{array}{c}\text { 土地利用 } \\
\text { 类型 }\end{array}$} & \multicolumn{2}{c}{ 面积变化 $/ \mathrm{km}^{2}$} & 增加量/ \\
\cline { 2 - 3 } & 2001 年 & 2006 年 & $\%$ \\
\hline 城镇 & 1028.8 & 1671.2 & 62.4 \\
水田 & 2616.8 & 1871.4 & -28.5 \\
早地 & 69.1 & 177.9 & 157.5 \\
林地 & 77.5 & 76.7 & -1.0 \\
水域 & 46.0 & 41.0 & -10.9 \\
\hline
\end{tabular}

表 2 张家港国民经济主要指标

Tab.2 Major economic indicators of Zhangjiagang

\begin{tabular}{ccc}
\hline 国民经济主要指标 & 2002 年 & 2015 年 \\
\hline 总人口/(万人) & 85.27 & 125.31 \\
非农业人口/(万人) & 34.96 & 83.94 \\
城镇化水平/\% & 41.00 & 66.99 \\
地区生产总值/( 亿元) & 365.02 & 2229.82 \\
人均生产总值/( 亿元) & 4.28 & 24.20 \\
农业总产值/(亿元) & 19.44 & 33.89 \\
农作物播种面积 $/ \mathrm{km}^{2}$ & 714.53 & 521.40 \\
\hline
\end{tabular}

$\beta$ 为河网中河链数与节点数之比, 反映了每个节点 平均所连的河链数, $\beta$ 小于 1 时, 水系为树状结构; $\beta$ 大于 1 时, 水系为格状结构或回路结构. $\gamma$ 为河网中实际连接 线数与最大可能连接线数之比, 反映了河网水系各河道 间实际连通程度, 取值在 $0 \sim 1$ 之间、接近 $1 / 3$ 时, 水系为 树状结构; 接近 1 时, 水系各节点间都相互连通 ${ }^{[19-20,25]}$.

\section{3 研究区城市化进程}

城市化通常是指农村人口向城市迁移的过程 ${ }^{[26]}$, 表 现为非农村人口所占比例的增加, 农业用地向城市建设 用地的转变. 本文主要采用非农业人口比重来表征张家 港区域城市化水平.

由 2001-2006 年武澄锡虞区土地利用类型面积 ${ }^{[11]}$ 的变化可以看出, 城镇用地和旱地的面积有快速增加的 趋势, 而水田、林地、水域的面积呈减小趋势 (表 1). 旱地 面积的增加量最为明显, 5 年约增加了 1.5 倍, 同时城镇 用地面积增加了 $62.4 \%$, 因此位于该区域的张家港在此 期间城市化进程明显.

2002-2015 年张家港非农业人口的比重发生了显 著的变化, 由 $41.00 \%$ 上升至 $66.99 \%$ (表 2), 因此该阶段 研究区城市化进程明显. 同时总人口、地区生产总值与 人均生产总值也增长迅速, 但是与此同时农作物播种面 积却发生了减少, 减少了约 $27 \%$, 从另一方面表现出了 张家港在这 13 年间城市化成果显著, 原本用于农作物播

种的区域逐渐向城镇发展用地转化,转化过程中的填河造地等活动导致了河道面积的缩减.

\section{4 数据基础}

本文河网水系分析研究使用的数据资料为张家港市水资源管理处提供的 2002 年和 2015 年两个时期的 张家港市 1:50000 的数字化水系图, 在数字化中, 将湖泊、池塘作为面状水系, 河流作为线状水系, 由于张家 港地区面状水系较少, 便于统计将其忽略, 本文主要统计线状水系, 同时忽略两端不与河网相连的河道. 在 绘制水系图时,将干流绘制为宽度 $2 \mathrm{~mm}$ 的河道, 其余河道线宽为 $1.5 \mathrm{~mm}$ (图 2).
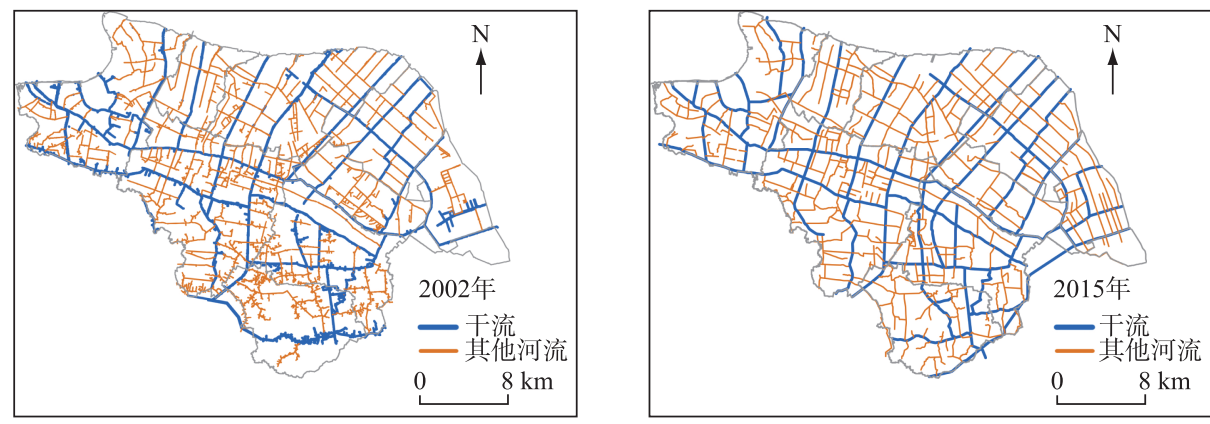

图 22002 年和 2015 年研究区水系

Fig.2 River system of research area in 2002 and 2015 


\section{3 结果与讨论}

\section{1 水系结构变化}

3.1.1 全区水系结构变化 图 2 为研究区不同时期的 水系图,区域水系结构参数计算结果见表 3 .

随着城市化的发展, 研究区的河流总数减少了 约 149 条, 总长度减少约 $155.6 \mathrm{~km}$, 年均减少 12.0 $\mathrm{km}$, 总面积减少约 $4.2 \mathrm{~km}^{2}$, 与河道长度相比, 总面积 变化较小. 从河流形态上看, 2002-2015 年间三级河 道大幅减少,变化剧烈, 长度减少了 $192.9 \mathrm{~km}$, 面积 减少了约 $4.0 \mathrm{~km}^{2}$, 占总消失面积的 $95.2 \%$, 这与城市 化进程中河网水系的改造有关, 河宽较小的低等级 河道被填埋. 与此同时, 由于平原河网地区防洪排涝及调水引流的需求, 部分河道进行了拓宽工程, 另外,城 市化进程中河道出现降级现象, 部分一级河流宽度降低被划分为二级河流, 因此二级河道总长度增加了 $102.1 \mathrm{~km}$, 占原二级河道长度的 $21.1 \%$, 面积增加了约 $1.3 \mathrm{~km}^{2}$, 一级河道总长度减少了 $64.8 \mathrm{~km}$, 总面积减少 了 $1.5 \mathrm{~km}^{2}$, 由于一级河道多为城市水系规划中的骨干河道, 总体变化相对较小.

研究区水面率从 3.38\% (2002 年) 降低到 2.85\% (2015 年), 变化率为- $15.7 \%$ (表 3), 杨凯等 ${ }^{[21]}$ 从保护 平原河网水系和保证河网功能为目的,建议上海平原河网地区的水面率不低于 $9 \%$, 在未考虑张家港地区面 状水系及双山岛旅游度假区水系的前提下, 研究区平均水面率远低于该值, 需引起重视. 河网密度从 1.56 $\mathrm{km} / \mathrm{km}^{2}$ (2002 年)减少到 $1.36 \mathrm{~km} / \mathrm{km}^{2}$ (2015 年), 降低了 $12.6 \%$. 与此同时, 河频率的变化达到 $-33.3 \%$, 远大 于水面率与河网密度降低的程度, 这是因为在城市发展建设中人为进行了河流的填埋, 低等级河流大量消 失, 而低等级河流本身的河长、河宽相对较小, 因此整体河网密度与水面率的衰减程度小于河频率. 干流面 积长度比减小幅度较小, 基本维持在 $0.03 \mathrm{~km} / \mathrm{km}^{2}$ 左右, 说明研究区主干河流面积与长度的发育同步性较好.

\section{1 .2 水系结构变化的空间分异 (1) 各区水系结构参数变化.}

1) 水面率:如图 3 所示, 除常阴沙现代农业示范区外, 其余 8 镇的水面率都有所降低, 减小幅度在 $4.8 \%$ 28.0\% , 常阴沙的水面率在此期间增加了 $52.3 \%$,增幅较大. 8 镇的变化具有同步性, 虽然衰减率有所 差别, 但变化前后水面率高低排序变化较小. 2002 年水面率最大的是杨舍镇, 为 $4.6 \%$, 最小的是大新镇 $(2.2 \%)$, 同时大新镇也是水面率衰减程度最小的地区, 13 年间仅减少了 $4.8 \%$, 而杨舍镇是衰减率最大的地 区, 达到了 $28.0 \%$, 这与杨舍镇是张家港的城市中心有关, 由于城市的建设需求, 中小型河流被大量填埋. 常 阴沙主要以发展现代化农业为主, 灌溉和养殖的需求使该地区在发展中进行了有规划的新河道开挖工程, 从水系图 (图 2) 可以看出该地区河道分布较为规律.

2)河网密度: 常阴沙与大新镇的河网密度增幅分别为 $39.8 \% 、 17.2 \%$, 其余 7 镇河网密度的变化率在 $-30.2 \% \sim-2.3 \%$ 范围内. 除常阴沙外, 2002 年河网密度最大的地区为杨舍镇, 为 $2.0 \mathrm{~km} / \mathrm{km}^{2}$, 最小的是乐余 镇 $\left(1.2 \mathrm{~km} / \mathrm{km}^{2}\right)$, 大新镇的河网密度经过城市化发展由 $1.3 \mathrm{~km} / \mathrm{km}^{2}$ 增加到 $1.5 \mathrm{~km} / \mathrm{km}^{2}$, 成为 2015 年河网密 度第二高的地区, 仅次于杨舍镇 $\left(1.6 \mathrm{~km} / \mathrm{km}^{2}\right)$. 河网密度衰减程度最高的是南丰镇, 衰减率达到了 $30.2 \%$; 衰 减程度最低的地方是塘桥镇, 只有 $2.3 \%$. 水面率与河网密度的衰减表现出了河网面积与长度变化的不同步 性, 水面率衰减程度最高的是杨舍镇、金港镇, 而河网密度衰减程度最高的是南丰镇、锦丰镇, 后二者河网密 度减小的主要原因是区域内宽度较小的低等级河流的消失. 常阴沙河网密度的增幅小于水面率.

3) 河频率: 8 镇的河频率衰减率在 4.0\% 68.0\% 之间,地区差异大, 常阴沙在此期间的增长率为 $26.9 \%$. 河频率的分布在 2002 年空间差异明显, 最高的是南丰镇和风凰镇, 最低的乐余镇, 为 0.3 条 $/ \mathrm{km}^{2}$. 经历了平 原河网的多年衰减后,除常阴沙外,2015 年各区河频率空间差异减小, 分布较为均衡, 原先河频率较高的 3 个地区 (南丰镇、凤凰镇和塘桥镇) 变化程度较大, 分别为 $-68.0 \% 、-53.2 \%$ 和 $-53.4 \%$, 衰减后河频率最大的 地区为凤凰镇 $\left(0.5\right.$ 条 $\left./ \mathrm{km}^{2}\right)$, 乐余镇几乎没有衰减. 常阴沙现代农业示范区在发展中除了新河道的开挖, 也 对已有河道进行了拓宽、延长等工程, 因此河道数量 (河频率) 的增长率小于水面率与河网密度. 
4) 河网复杂度: 常阴沙和金港镇的河网复杂度随着城市化分别增加了 $65.8 \% 、 12.7 \%$,其余 7 镇河网复 杂度的衰减率在 $-51.4 \% \sim-20.0 \%$ 之间, 从这个变化中可以看出整个张家港地区的河网在城市化进程中有 主干化的趋势. 河网复杂度的空间差异性非常明显, 大新镇在 2002 年的河网复杂度最大, 为 20.3 , 在经过了 $-22.2 \%$ 的变化后为 15.8 , 依然是最高的地区, 从大新镇 $17.2 \%$ 的河网密度增长率可以看出, 虽然该地区河网 复杂度下降,但河道总长的增加使该地区河网复杂程度依然高于其他区域. 常阴沙现代农业示范区的河网 复杂度在 2002 年最低, 为 4.5 , 在水系变化的过程中, 大量中小型河流的增加使主干河道比例减小, 因此经历 $24.3 \%$ 的增长后变为 5.6. 金港镇位于长江边, 原本河网中干流水系发达, 城市化进程中该地区干流的衰减程 度大于其他河流,因此 2002-2015 年主干河道所占比重减小,使该地区河网复杂度增长了 $12.7 \%$. 南丰镇 3.9 的河网复杂度在 2015 年为最低, 衰减率也是全区最高, 达到了 $51.4 \%$, 这与其河频率、河网密度的变化相 符, 大量低等级河道的消失使它成为主干化最明显的地区, 河网层次趋于简单化.
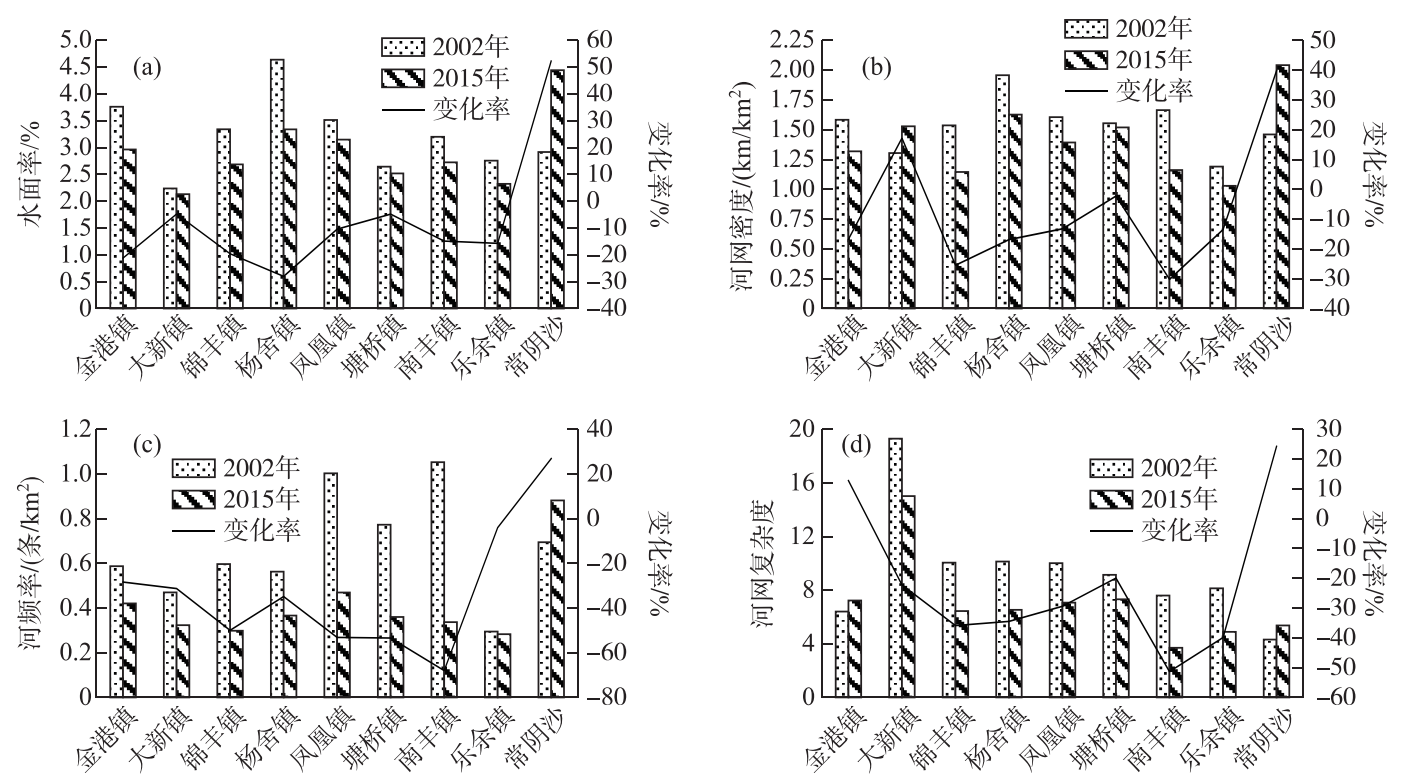

图 32002 年和 2015 年各行政单元水系结构参数及变化率

Fig.3 Structural parameters of river system and its change rate of each administrative unit in 2002 and 2015

(2) 空间分异性.

从空间分布来看, 水面率与河网密度较大的地区都集中在张家港支流水系较为发达的南部, 沿江的北 部地区较小; 水面率衰减程度最剧烈的区域位于西南部, 东部衰减程度较低 (图 4a); 除南丰镇、锦丰镇和大 新镇外, 其余地区河网密度的衰减率较为平均 (图 4b). 2002 年河频率最高的东南部地区在经过 13 年的城 市化后衰减程度最剧烈 (图 4c), 衰减后除常阴沙外, 其余地区河频率较为接近, 但总体上南部比北部更高. 河网复杂度衰减最剧烈的地区位于张家港东北部( 图 4d).

张家港南北河流形态具有差异性, 南部多为自然发育形成的河流, 呈弯曲型,形态多样化; 北部多为人 工开挖的河流, 呈顺直型 ${ }^{[17]}$, 因此在城市化带来的水系改造活动大量进行前, 南部较北部水系在河道面积、 长度、数量上有优势. 水系的 “井型结构” 被认为是平原地区经人工改造后一种可以满足河道各种功能需求 的水系结构 ${ }^{[27]}$, 由图 2 可以看出, 2002 年张家港北部沿江的乐余镇、锦丰镇区域内有较为明显的近“井型结 构” 水系, 经过 13 年城市化改造后, 北部区域的 “井型结构” 更为明显, 南部区域有向 “井型结构” 变化的趋 势, 该区域经自然发育形成的低等级河流大量消失, 以此来满足城市化导致的建设用地需求的增加, 这与美 国俄克拉荷马雷鸟湖流域的研究 ${ }^{[28]}$ 结果相似, 因此南部区域的水面率和河频率较北部有更大程度的衰减.

由此看出城市化对水系结构的影响程度不但取决于城市的发展建设,也基于原来水系的形态. 太湖流 
域平原河网区的水系为自然发育河流与人工河渠共存的综合水系,随着城市化发展,自然发育河流为主的 水系在水面率 (河道面积)、河网密度 (河道长度)、河频率 (河道数量) 上会有较大的衰减, 而人工河渠为主 的水系变化相对较小.
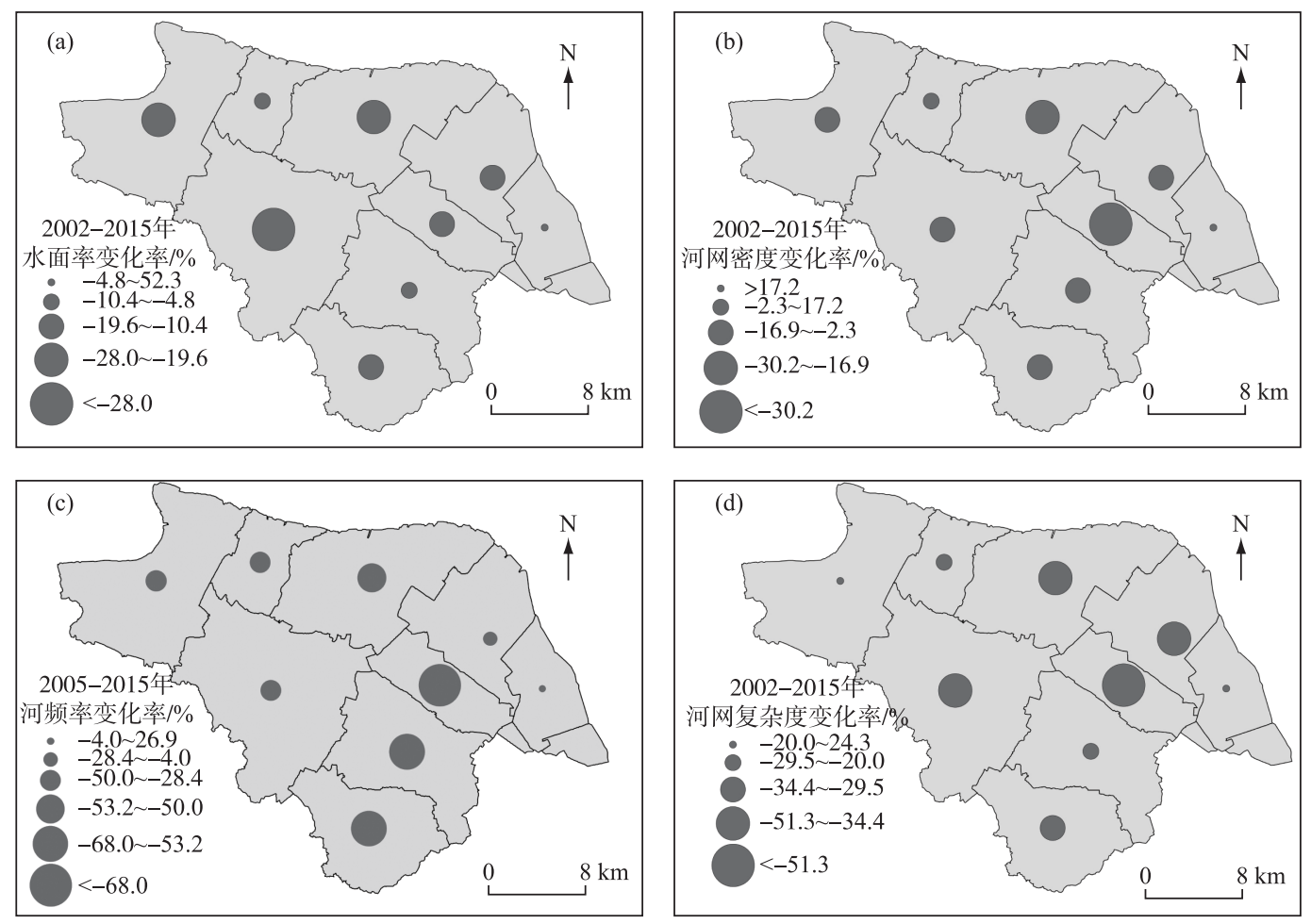

图 4 各时期分区水系结构参数及变化率

Fig.4 Structural parameters and change rate of water system in each period

\section{2 连通性变化}

城市化对水系结构连通性变化影响显著. 研究区河链数由 2002 年的 1748 减少到 2015 年的 949 , 减少 率达到了 $45.7 \%$, 减少了近一半; 节点数在 2002 年为 1445,2015 年只有 719 , 减少率高达 $50.2 \%$. 随着城市的 发展, 大量低等级河流的消失导致地图上河链与节点数的大幅减少, 但河链的平均长度却在这期间有所增 加, 由原来的 $0.71 \mathrm{~km}$ 增加为 $1.14 \mathrm{~km}$, 这与城市化中河流的主干化趋势有关, 与低等级河流不断消失同时发 生是高等级河流的拓宽与建设, 因此河链平均长度增加了; 同时, 由节点数减少率大于河链数可知, 相同长 度河链上出现的平均节点数必定有所减少, 由此也能解释河链平均长度的增加 (表 4).

研究区整体与各区不同时期的河网水系线点率与实际连通度如表 4 和图 5 所示, 2015 年与 2002 年相 比, 整体的线点率 $\beta$ 由 1.21 增加到 1.32 , 实际连通度由 0.40 增加到 0.44 , 变化较小, 连通性略有提高. 但是 从各区分别来看, 其中杨舍镇、塘桥镇、凤凰镇、南丰镇与常阴沙现代农业示范区五个地区内, 线点率与实际 连通度呈现减小的趋势, 河网各节点之间的连通能力在减弱, 河道之间的畅通程度随着城市化发展而变弱. 与此同时,金港镇、锦丰镇、乐余镇和大新镇的线点率与实际连通度有所增加, 说明该区域河网各节点间的 通达能力有所加强.

从空间上来看, 河网连通能力加强的地区集中在张家港西北部地区, 而东南部区域河网畅通程度减弱, 这与上文所提到的张家港水系的南北差异有关, 东南部地区为离江较远的内河区域, 原本的支流水系较沿 江地区更为发达, 在城市化进程中受人类活动干扰, 水系结构变化更多, 同时, 为低洼农田修建的圩区的增 加影响了自然水系的毛细结构, 加速了低等级河道的消亡, 使原本的水系格局被打乱, 河道被切断 ${ }^{[17]}$. 
表 4 研究区河网连通性参数变化情况

Tab.4 Parameters of river connectivity in study area

\begin{tabular}{cccccc}
\hline 时间 & 河链 & 节点 & 河链平均长度 $/ \mathrm{km}$ & 线点率 $(\beta)$ & 实际连通度 $(\gamma)$ \\
\hline 2002 年 & 1748 & 1445 & 0.71 & 1.21 & 0.40 \\
2015 年 & 949 & 719 & 1.14 & 1.32 & 0.44 \\
\hline
\end{tabular}

在研究区水系由自然型向主干型与 “井型结构”变化的过程中, 河网原本自身调蓄与排水的功能遭到破 坏, 水动力减弱, 进而需借助新建水闸、泵站增强河流的调蓄能力, 而水闸、洜站的调度需要基于历史观测数 据、实时情况、各区域需求甚至局部水质情况及时调整, 不合理的调度不但无法增强河流的调蓄能力,还会破 坏生态环境, 对水资源造成不可逆的损害. 目前城市化带来的人工河渠为主的河网需要更合理的人工干预才能 增强并维持水体的连续性和连通性, 让河流保持健康, 水资源可持续利用, 实现水系的调蓄功能与生态效益 ${ }^{[29]}$.
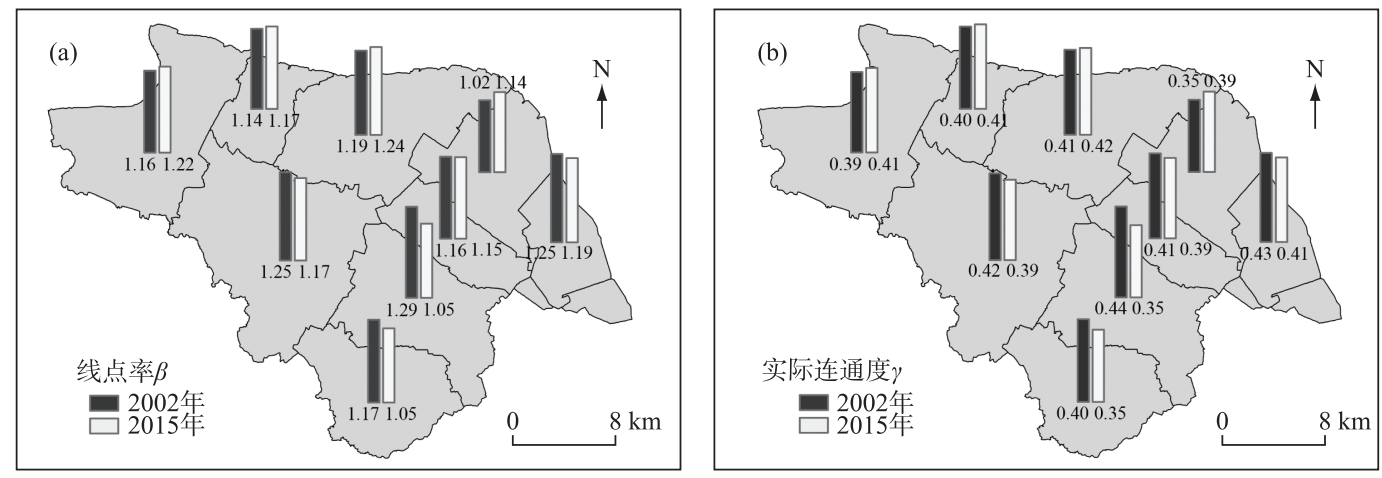

图 5 各时期分区河网连通性参数情况

Fig.5 The connectivity parameters of the river network in different periods

\section{3 城市化与水系结构指标的关系}

对不同行政区不同时期河网水系结构参数与人口、GDP 进行相关水平分析表明: 在两个时期, 水面率与 人口、GDP 之间相关水平均较高, 呈正相关关系, 说明不论什么时期, 河网地区的水面率与可表征城市化水 平的国民经济指标密切相关;2002 年河网密度 $\left(R_{\mathrm{d}}\right)$ 与人口、GDP、水面率之间相关水平较高, 2015 年水面率 与河频率密切相关. 因此不同行政区河网水系结构参数的空间分异与各地区国民经济发展以及城市化水平 有关.

将对河网水系结构参数变化与国民经济指标变化进行相关水平分析表明: GDP 变化率、水面率变化率 与河网密度变化率两两之间相关水平普遍较高, 其中 GDP 变化与水面率变化、河网密度变化均为负相关关 系,显示随着 GDP 的迅速增长, 水面率与河网密度的衰减程度较高. 因此各区域河网水系结构参数变化率 的空间分异与不同地区 GDP 水平变化(城市化水平变化)的地区差异密切相关.

表 52002 年河网水系结构参数与国民经济指标之间的相关分析

Tab.5 Correlation coefficient between stream structure parameters and economic indicators in 2002

\begin{tabular}{ccccccc}
\hline & 人口 & GDP & $W_{\mathrm{P}}$ & $R_{\mathrm{d}}$ & $R_{\mathrm{f}}$ & $C R$ \\
\hline 人口 & 1 & & & & & \\
GDP & $0.94^{* * *}$ & 1 & & & & \\
$W_{\mathrm{P}}$ & $0.84^{* *}$ & $0.75^{*}$ & 1 & & & \\
$R_{\mathrm{d}}$ & $0.64^{*}$ & $0.68^{*}$ & $0.84^{* *}$ & 1 & & \\
$R_{\mathrm{f}}$ & -0.30 & -0.17 & 0.143 & 0.48 & 1 & 1 \\
$C R$ & -0.34 & -0.33 & -0.46 & -0.31 & -0.26 & 1 \\
\hline
\end{tabular}


表 62015 年河网水系结构参数与国民经济指标之间的相关分析

Tab.6 Correlation coefficient between stream structure parameters and economic indicators in 2015

\begin{tabular}{ccccccc}
\hline & 人口 & GDP & $W_{\mathrm{P}}$ & $R_{\mathrm{d}}$ & $R_{\mathrm{f}}$ & $C R$ \\
\hline 人口 & 1 & & & & & \\
GDP & $0.88^{* *}$ & 1 & & & & \\
$W_{\mathrm{P}}$ & $0.71^{*}$ & $0.64^{*}$ & 1 & & & \\
$R_{\mathrm{d}}$ & 0.41 & 0.20 & 0.29 & 1 & & \\
$R_{\mathrm{f}}$ & 0.22 & 0.17 & $0.69^{*}$ & 0.42 & 1 & 1 \\
$C R$ & -0.21 & -0.19 & -0.43 & 0.55 & -0.02 & \\
\hline
\end{tabular}

表 7 河网水系结构参数变化与国民经济指标变化之间的相关分析

Tab.7 Correlation coefficient between the change rate of stream structure parameters and economic indicators

\begin{tabular}{|c|c|c|c|c|c|c|}
\hline & 人口变化率 & GDP 变化率 & $\begin{array}{l}\text { 水面率 } \\
\text { 变化率 }\end{array}$ & $\begin{array}{c}\text { 河网密度 } \\
\text { 变化率 }\end{array}$ & $\begin{array}{l}\text { 河频率 } \\
\text { 变化率 }\end{array}$ & $\begin{array}{c}\text { 河网复杂度 } \\
\text { 变化率 }\end{array}$ \\
\hline 人口变化率 & 1 & & & & & \\
\hline GDP 变化率 & 0.39 & 1 & & & & \\
\hline 水面率变化率 & -0.23 & $-0.66^{*}$ & 1 & & & \\
\hline 河网密度变化率 & -0.33 & $-0.70^{*}$ & $0.66^{*}$ & 1 & & \\
\hline 河频率变化率 & -0.58 & -0.38 & -0.20 & 0.32 & 1 & \\
\hline 河网复杂度变化率 & -0.24 & 0.08 & 0.01 & 0.33 & 0.27 & 1 \\
\hline
\end{tabular}

$* 0.05$ 水平上显著相关, $* * 0.01$ 水平上显著相关, $* * * 0.001$ 水平上显著相关 (表中数据均为 $R^{2}$ 值).

\section{4 城市化与连通性指标的关系}

将研究区整体河网连通性参数与总人口、城镇化水平、农作物播种面积的变化率进行对比分析表明 (表 8): 随着城市化进程, 河链数、节点数变化率与总人口、城镇化水平变化率的数值具有同步性, 河链数、节点 数与农作物播种面积有相似的减小趋势, 说明河链与节点受城市化影响较大, 这与河网主干化趋势有关, 河 网的衰退必然导致河链数与节点数的减少.

研究区整体的线点率、实际连通度变化较小, 没有随城市化指标而改变, 这是因为本文所提连通性为结 构连通性,从水系结构来看,南部与北部的河网变化具有空间分异性,河网畅通程度减弱与增强的地区同时 存在,因此整体变化不大, 由此看出, 无法通过地区的城市化程度直接推断该地区河网水系结构连通性的 变化.

表 8 河网连通性参数与国民经济指标变化

Tab.8 Change rate of connectivity parameters of the river network and economic indicators

\begin{tabular}{cccccccc}
\hline & 河链 & 节点 & 线点率 $(\beta)$ & $\begin{array}{c}\text { 实际连通度 } \\
(\gamma)\end{array}$ & $\begin{array}{c}\text { 总人口/ } \\
(\text { 万人 })\end{array}$ & $\begin{array}{c}\text { 城镇化水平/ } \\
\%\end{array}$ & $\begin{array}{c}\text { 农作物播种 } \\
\text { 面积 } / \mathrm{km}^{2}\end{array}$ \\
\hline 2002 年 & 1748 & 1445 & 1.21 & 0.40 & 85.27 & 41.00 & 714.53 \\
2015 年 & 949 & 719 & 1.32 & 0.44 & 125.31 & 66.99 & 521.40 \\
变化率/\% & -45.7 & -50.2 & 9.1 & 10.0 & 47.0 & 63.40 & -27.0 \\
\hline
\end{tabular}

\section{4 结论}

1) 太湖流域典型沿江城市张家港在 2002-2015 年间, 水面率变化幅度为 $-15.7 \%$, 河网密度降低了 $12.6 \%$,河频率变化了 $-33.3 \%$, 河网衰减, 低等级河道大量消失, 有主干化趋势, 但干流面积与长度发育的同 步性较好; 河网水系结构在城市化影响下的变化具有明显的空间分异. 常阴沙现代农业示范区河网呈发展 趋势, 河道数量、长度、密度均有增加; 南部水系较北部水面率与河频率衰减更剧烈; 河网密度除东北部地区 
衰减较为剧烈外,其余区域变化较为平均; 从河网复杂度的变化可以明显看出主干化较为明显的是东北部; 太湖流域平原河网区以自然发育河流为主的水系随着城市化会有较大的衰减, 人工河渠为主的水系变化相 对较小.

2) 全区连通性略有提高, 但地区分异明显, 沿江的西北部地区河网连通能力有所加强, 而东南部内河区 域河网畅通程度减弱; 被圩区、水闸与葲站切断的水系需要更合理的调度方案才能增强并维持水体的连通 度, 实现水系的调蓄功能与生态效益.

3 ) 水面率与人口、GDP 之间相关水平均较高; GDP 变化与水面率变化、河网密度变化均为密切的负相 关关系;各地区水系结构参数与其变化率的空间分异与该地区人口、经济发展水平密切相关;

4) 河网河链数、节点数受城市化影响较大, 河网的衰退必然导致河链数与节点数的减少; 研究区河网线 点率、实际连通度的变化与城市化指标相关性较弱, 无法通过太湖流域平原河网地区的城市化程度直接推 断该地区河网水系结构连通性的变化.

本文所选取的评价水系结构的基本指标与基于景观生态学、图论的连通性指标可以基本反映太湖流域 平原河网地区河道的变化情况, 为后期该地区如何更好地优化水系结构, 合理发挥河道的防洪、调蓄功能提 供了基础,并且基于分片区的研究更有利于各行政区域开展因地制宜的管理. 但太湖流域平原河网地区河 道水流受闸、泵开闭影响大, 在不同调度情况下连通性有所差别, 所以本文连通性的研究具有一定局限性, 如何使人工河渠为主的河网水系保持较好的结构连通性与水文连通性还有待进一步探索.

\section{5 参考文献}

[ 1 ] Gregory KJ. The human role in changing river channels. Geomorphology, 2006, 79(3/4) : 172-191. DOI: 10.1016/j.geomorph.2006.06.018.

[ 2 ] Nilsson C, Reidy CA, Dynesius M et al. Fragmentation and flow regulation of the world's large river systems. Science, $2005, \mathbf{3 0 8}(5720)$ : 405-408. DOI: 10.1126/science.1107887.

[ 3 ] Anne C. Urban transformation of river landscapes in a global context. Geomorphology, 2006, 79(3/4) : 460-487. DOI: 10.1016/j.geomorph.2006.06.033.

[ 4 ] Shao YL. Changes of river network structure and connectivity of Taihu Lake Basin and its influence on floods [Dissertation]. Nanjing: Nanjing University, 2013. [邵玉龙. 太湖流域水系结构与连通变化对洪涝的影响研究 [ 学位论文]. 南京: 南京大学, 2013.]

[ 5 ] Wang ST. Study on the impact of urbanization on stream structure, river network connectivity and storage capacity in Nanchang[Dissertation]. Nanchang: Nanchang University, 2016. [王世涛. 城市化发展对南昌市水系结构与河网连通性 变化及其调蓄能力的影响研究 [学位论文]. 南昌: 南昌大学, 2016.]

[6 ] Fu C, Li YY, Wang ST. Analysis of water system structure and connectivity in the center of Nanchang under the urbanization process. Resources and Environment in the Yangtze Basin, 2017, 26(7) : 1042-1048. [傅春, 李云翊, 王世涛. 城市 化进程下南昌市城区水系格局与连通性分析. 长江流域资源与环境, 2017, 26(7): 1042-1048.]

[ 7 ] Jin M. Research on the urbanization response of interconnected river system network in Zhengzhou City [Dissertation]. Zhengzhou: Zhengzhou University, 2014. [靳梦. 郑州市水系连通的城市化响应研究 [学位论文]. 郑州: 郑州大 学, 2014.]

[ 8 ] Chen YX, Xu YP, Fu WJ. Influences of urbanization on river network in the coastal areas of East Zhejiang province. Advances in Water Science, 2007, 18 (1) : 68-73. [陈云霞, 许有鹏, 付维军. 浙东沿海城镇化对河网水系的影响. 水科 学进展, 2007, 18(1): 68-73.]

[ 9 ] Wang LY, Xu YP, Yu MJ. Analysis of the urbanization effect on the Taihu Plain River Network — A case study of Wuchengxiyu region of Taihu Basin. Resources and Environment in the Yangtze Basin, 2012, (2): 151-156. [王柳艳, 许 有鹏, 余铭婧. 城镇化对太湖平原河网的影响——太湖流域武澄锡虞区为例. 长江流域资源与环境, 2012, (2): 151-156.]

[10] Shao YL, Xu YP, Ma SS. Change of river structure and stream network connectivity in the Taihu Lake Basin under the urbanization development-A case study in urban Suzhou. Resources and Environment in the Yangtze Basin, 2012, 21(10): 1167-1172. [郡玉龙, 许有鹏, 马爽㸚. 太湖流域城市化发展下水系结构与河网连通变化分析一一以苏州市中心 区为例. 长江流域资源与环境, 2012, 21(10): 1167-1172.]

[11] Cai J. Study on the impact of urbanization on stream structure and regulation capacity in the center of Tai Lake Basin-A 
case study of Wuchengxiyu Region[Dissertation]. Nanjing: Nanjing University, 2012. [蔡娟. 太湖流域腹部城市化对水 系结构变化及其调蓄能力的影响研究——以武澄锡虞区为例 [学位论文]. 南京: 南京大学, 2012.]

[12] Meng HF, Xu YP, Xu GL et al. Study on rivers connectivity evaluation in plain river network area. Resources and Environment in the Yangtze Basin, 2014, (5) : 626-631. [孟慧芳, 许有鹏, 徐光来等. 平原河网区河流连通性评价研究. 长 江流域资源与环境, 2014, (5):626-631.]

[13] Xu H, Xu XY, Cui GB. Application of landscape spatial structure analysis to urban river system planning. Advances in Water Science, 2007, 18(1) : 108-113. [徐慧, 徐向阳, 崔广柏. 景观空间结构分析在城市水系规划中的应用. 水科学 进展, 2007, 18(1): 108-113.]

[14] Xu GL. Changes of river network structure and connectivity of Taihu lake basin and its influence on hydrology process[Dissertation]. Nanjing: Nanjing University, 2012. [徐光来. 太湖平原水系结构与连通变化及其对水文过程影响研究 [学位论文]. 南京: 南京大学, 2012.]

[15] Lane S, Reaney S, Heathwaite A. Representation of landscape hydrological connectivity using a topographically driven surface flow index. Water Resources Research, 2009, 45. DOI: 10.1029/2008WR007336.

[16] Wang LC, Shi YL, Zhou YK. Strategy for water environment treatment in the Yangtze delta. Resources and Environment in the Yangtze Basin, 2003, 12(3) : 223-227. [王腊春, 史运良, 周寅康. 长江三角洲水环境治理. 长江流域资源与环 境, 2003, 12(3): 223-227.]

[17] Zhang JT, Liu J. Discussion about the layout of water system in Zhang-jia-gang City. South-to-North Water Transfers and Water Science \& Technology, 2006, (4) : 44-46. [张建涛, 刘俊. 张家港市水系规划. 南水北调与水利科技, 2006, (4) : 44-46.]

[18] Han Longfei, Xu Youpeng, Lei Chaogui et al. Degrading river network due to urbanization in Yangtze River Delta. Journal of Geographical Sciences, 2016, 26(6) : 694-706. DOI: 10.1007/s11442-016-1293-0.

[19] Shen J. Study on the impact of urbanization on stream structure, river network connectivity and storage capacity in pudong new area, Shanghai[Dissertation]. Shanghai: East China Normal University, 2015. [沈洁. 上海浦东新区城市化进程 对水系结构、连通性及其调蓄能力的影响研究 [学位论文]. 上海: 华东师范大学, 2015.]

[20] Ma SS. Study on river network pattern and connectivity of Hangzhou-Jiaxing-Huzhou plain region based on river health [Dissertation]. Nanjing: Nanjing University, 2013. [马爽爽. 基于河流健康的水系格局与连通性研究 [学位论文]. 南京: 南京大学, 2013.]

[21] Yang K, Yuan W, Zhao J et al. Stream structure characteristics and its urbanization responses to tidal river system. Acta Grographica Sinica, 2004, 59(4): 557-564. [杨凯, 袁雯, 赵军等. 感潮河网地区水系结构特征及城市化响应. 地 理学报, 2004, 59(4): 557-564.]

[22] Qiang PP. Research on river corridor planning theory and application[Dissertation]. Dalian: Dalian University of Technology, 2011. [强盼盼. 河流廊道规划理论与应用研究 [学位论文]. 大连: 大连理工大学, 2011.]

[23] Wang YC. The connectivity evaluation of Shanghai urban landscape eco-network. Geographical Research, 2009, 28(2) : 284-292. [王云才. 上海市城市景观生态网络连接度评价. 地理研究, 2009, 28(2) : 284-292.]

[24] Xu JM. Exploration of Graph Theory and Theoretical Physics. Education and Modernization, 1997, (2) : 41-46. [徐俊明. 《图论及其应用》课程建设探索. 教育与现代化, 1997, (2) : 41-46.]

[25] Zhao J. Landscape pattern change and its environmental response across multiple spatial scales in tidal plain[Dissertation]. Shanghai : East China Normal University, 2008. [赵军. 平原河网地区景观格局变化与多尺度环境响应研究一一上 海地区为例 [学位论文].上海: 华东师范大学, 2008.]

[26] Chen S, Wang J. Level of urbanization and assessment of impacts of immigratory popilation in the Taihu Watershed. Resources and Environment in the Yangtze Basin, 2004, 13(6) : 524-529. [ 陈爽, 王进. 太湖流域城市化水平及外来人口 影响测评. 长江流域资源与环境, 2004, 13(6) : 524-529.]

[27] Yuan W, Yang K, Wu JP. River structure characteristics and classification system in river network plain during the course of urbanization. Scientia Geographica Sinica, 2007, 27(3): 401-407. [袁雯, 杨凯, 吴建平. 城市化进程中平原河网 地区河流结构特征及其分类方法探讨. 地理科学, 2007, 27(3) : 401-407.]

[28] Wang ZG, Li ZL, Liu CM et al. Discussion on water cycle mechanism of interconnected river system network. Journal of Natural Resources, 2011, 26(3) : 523-529. [王中根, 李宗礼, 刘昌明等. 河湖水系连通的理论探讨. 自然资源学 报, 2011, 26(3): 523-529.]

[29] Jasonp J, Nicholasa W, de Kirstenm B et al. Long-term impacts of land cover changes on stream channel loss. Science of the Total Environment, 2015, 537: 399-410. 